\title{
Pengolahan sabun berbahan dasar susu kambing sebagai potensi usaha di Desa Logandeng
}

\author{
Surya Putri Arum Sekar Kinanthi ${ }^{1}$, Aulia Rahmadhani ${ }^{2}$, Gregorius Niarwin ${ }^{3}$, Emilia Vicka Kurniastuti ${ }^{4}$, Jessica Prajnadewi ${ }^{5}$, Kadek \\ Bramantya Krinanta Putra ${ }^{6}$, Ulul Azmi ${ }^{7}$, Giovanny Inan Jelmau ${ }^{8}$, Jepri Yanus Buulolo ${ }^{9}$, Galih Indra Kusumajati ${ }^{10}$ \\ Caecilia Santi Praharsiwi ${ }^{11}$
}

Universitas Atma Jaya Yogyakarta, Jl. Babarsari 44 Yogyakarta 55281, Indonesia

Email: caecilia.santi@uajy.ac.id

Received: June $12^{\text {th }} 2021$; Revised: -; Accepted for Publication November 17 ${ }^{\text {th }} 2021$; Published: November $17^{\text {th }} 2021$

\begin{abstract}
Logandeng Village is located in Playen District, Gunung Kidul, Yogyakarta. This village is well known because every person or tourists who want to travel to Gunung Kidul Beach will pass it. Logandeng Village has several village products that have been developed, including processed food and handicraft products. This village, which is mostly farmland, is not making use of the yields of this potential. Therefore, this study aims to develop village potential that focuses on livestock products, namely processed goat milk which is used as natural soap as its basic ingredient.
\end{abstract}

Keywords - Goat Milk, Natural Soap, Logandeng Village, Yogyakarta

\begin{abstract}
Abstrak — Desa Logandeng terletak di Kecamatan Playen, Gunung Kidul, Yogyakarta. Desa ini cukup dikenal karena setiap orang atau wisatawan yang hendak berpergian ke Pantai Gunung Kidul akan melewatinya. Desa Logandeng memiliki beberapa produk desa yang sudah dikembangkan, antara lain hasil olahan berupa makanan dan olahan kerajinan tangan. Desa ini yang sebagian besar merupakan lahan peternakan justru kurang memanfaatkan hasil dari potensi tersebut. Oleh karena itu, penelitian ini bertujuan untuk mengembangkan potensi desa yang berfokus pada hasil peternakan yaitu olahan susu kambing yang dijadikan sabun alami sebagai bahan dasarnya.
\end{abstract}

Kata Kunci - Susu kambing, Sabun Alami, Desa Logandeng, Yogyakarta

\section{PENDAHULUAN}

Desa Logandeng adalah desa yang terletak di Kecamatan Playen Kabupaten Gunung Kidul, Daerah Istimewa Yogyakarta. Desa Logandeng terletak pada arah selatan Yogyakarta. Desa ini cukup terkenal karena akan dilewati jika hendak berpergian ke pantai Gunung Kidul. Sebagian besar desa ini dijadikan sebagai lahan peternakan dan perkebunan. Jumlah penduduk Desa Logandeng yang tercatat dalam data adalah 8.740 jiwa. Jumlah fasilitas pendidikan di Desa Logandeng ada 11 Taman Kanak-kanak (TK), memiliki 5 Sekolah Dasar (SD), 1 Sekolah Menengah Pertama (SMP), dan 1 Sekolah Menengah Atas (SMA). Kemudian untuk fasilitas kesehatan, desa ini tidak memiliki Rumah Sakit (RS), Puskesmas, maupun Rumah Bersalin. Namun desa ini memiliki sebuah apotek.

Desa Logandeng memiliki beberapa produk desa yang sudah dikembangkan sebagai lahan usaha. Produk tersebut kebanyakan berupa makanan dan kerajinan. Desa ini memiliki produk Bakpia Sari Rasa Pager dan Soto Tan Proyek dari sisi makanan, serta memiliki helm antik, kerajinan ukir siluet wajah, batik, dan furniture dari sisi kerajinan yang khususnya berupa kerajinan seni rupa terapan dan keterampilan.

Di sisi lain Desa Logandeng adalah desa yang kebanyakan masyarakatnya menjadi peternak dan sebagian kecil menjadi petani. Berdasarkan catatan dalam data Desa Logandeng memiliki populasi hewan ternak yang cukup besar, ada ternak jenis besar maupun ternak jenis kecil[1]. Hewan yang banyak di ternak masyarakat desa ini adalah ternak jenis kecil seperti kambing dan domba, sedangkan ternak jenis besar seperti sapi dan kerbau. Desa ini juga memiliki pasar hewan yang lumayan terkenal di Yogyakarta, nama pasar hewan tersebut adalah Pasar Hewan Siyonoharjo yang terletak di Jl. Ps. Sapi Desa Logandeng. Dari sisi peternakan ada banyak hal yang berpotensi untuk kita manfaatkan sebagai lahan usaha. Hasil peternakan yang umumnya dapat dikembangkan menjadi usaha ada daging, kulit, susu, bahkan kotorannya. Namun dari hasil pengamatan kami ada beberapa jenis usaha baru yang bisa dikembangkan seperti usaha sabun susu yang mendukung gerakan cinta alam, desa wisata peternakan sebagai wadah edukasi, maupun membuat pupuk dari kotoran hewan ternak.

Dari beberapa potensi tersebut, tim ini memutuskan untuk mengembangkan usaha sabun susu dari hewan ternak kambing. Sebab susu kambing memiliki kandungan alami yang bagus untuk kulit sehingga nantinya para konsumen akan mendapatkan banyak manfaat dari sabun susu kambing alami ini khususnya untuk perawatan kulit sehat. Selain itu produk ini dapat dikembangkan sebagai produk lokal khas Desa Logandeng yang nanti dapat didistribusikan keluar desa maupun sebagai buah tangan atau oleh-oleh khas Desa Logandeng. Pengembangan produk lokal ini nantinya juga akan menambah kekayaan lokal pada desa.

Tujuan yang ingin dicapai yaitu mengembangkan salah satu usaha dari beberapa potensi desa yang dimiliki. Usaha tersebut ialah produk susu kambing yang mutu dan kualitasnya dijamin alami karena berasal dari susu segar hasil peternakan Desa Logandeng. Harapannya produk ini dapat menambah kekayaan lokal pada desa dan menjadi oleh-oleh khas Desa Logandeng dan mampu dipasarkan sampai keluar desa sehingga pada akhirnya Desa Logandeng memiliki ciri khas produk dan mensejahterakan warga desa itu sendiri. 


\section{Metode Pengabdian}

Dalam pelaksanaan program pengabdian masyarakat ini ini seluruhnya dilakukan secara daring dikarenakan adanya pandemi COVID-19. Oleh karena itu, baik dari pengumpulan data, pemetaan informasi hingga pembuatan output dilakukan secara daring. Adapun tahapan pelaksanaan program kerja tim sebagai berikut:

\section{A. Pengumpulan data}

Tim menggunakan objek penelitian yakni Desa Logandeng, Kecamatan Playen, Kabupaten Gunung Kidul, Daerah Istimewa Yogyakarta. Metode pengumpulan data yang dilakukan ialah metode penelusuran data online. Metode penelusuran data online menurut Bungin adalah suatu cara penelusuran data melalui media online seperti internet dan media jaringan lainnya yang menyediakan fasilitas online[2]. Sehingga, sumber data yang digunakan oleh tim ialah data sekunder yakni data-data online dari website resmi Desa Logandeng yakni www.logandengplayen.desa.id.

\section{B. Pengolahan data:}

Setelah data berhasil dikumpulkan, tahap selanjutnya ialah melakukan pengolahan data atau pemetaan informasi. Pemetaan informasi ini dibagi menjadi dua yakni, potensi desa \& potensi usaha.

\section{Potensi Desa}

Potensi yang dimiliki desa secara fisik berupa tanah, air, cuaca, geografis, ternak, tanaman, dan sumber daya manusianya. Ada juga potensi yang berupa Lembaga Sosial, Lembaga Pendidikan, dan tim masyarakat [3]. Dari pengamatan tim, Desa Logandeng memiliki potensi yang besar di bidang peternakan. Hal ini karena kebanyakan masyarakatnya memiliki mata pencaharian sebagai peternak. Selain itu, Desa Logandeng memiliki populasi hewan ternak yang cukup besar baik ternak besar (seperti sapi dan kerbau) maupun ternak kecil (kambing dan domba).

2. Potensi Usaha

Berdasarkan potensi Desa Logandeng yang cukup besar di bidang peternakan, tim melihat ada beberapa potensi usaha baru yang dapat dikembangkan di desa ini seperti usaha sabun susu, desa wisata peternakan dan pupuk dari kotoran hewan ternak. Namun, tim memutuskan untuk secara khusus mengembangkan usaha sabun susu dari hewan ternak kambing.

\section{Teknik analisis data}

Setelah data tersebut diolah menjadi potensi desa dan potensi usaha, kemudian dianalisis menggunakan dua metode yakni Segmenting, Targeting, Positioning (STP) dan Strength, Weakness, Opportunity, Threat (SWOT). Tujuan utama dari strategi Segmenting, Targeting, Positioning (STP) menurut Tjiptono merupakan menempatkan suatu merk di pikiran pelanggan ataupun konsumen, sehingga merk itu akan mempunyai keunggulan bersaing yang berkelanjutan. Suatu keunggan bersaing produk akan dimiliki produk apabila barang tersebut menawarkan simbol penunjuk dan bernilai unik bagi pelanggan [4]. Beberapa kelebihan analisis
SWOT yaitu bentuk analisis ini dapat mengetahui setiap kekurangan dan kelebihan sebuah lembaga sehingga memiliki manfaat untuk mengurangi dampak yang mungkin terjadi di masa yang akan datang [5]. Sedangkan metode Strength, Weakness, Opportunity, Threat (SWOT) merupakan suatu pemahaman adanya banyak faktor yang secara teratur untuk menjelaskan strategi perusahaan, analisis SWOT ini bersumber pada pemikiran yang mampu memaksimumkan kekuatan (strength) dan peluang (opportunities), tetapi sekaligus dapat meminimalkan kelemahan (weakness) dan ancaman (threats) [6].

Dalam hal ini, yang dianalisis ialah potensi usaha desa yakni produk usaha sabun susu kambing. Metode STP digunakan tim untuk menganalisis produk sabun susu kambing mulai dari melihat segmentasinya, memutuskan target konsumennya, hingga menempatkan posisi sabun susu kambing sebagai sebuah brand di masyarakat. Lalu pada metode kedua yaitu SWOT, digunakan untuk menelusuri kekuatan (strength), kelemahan (weakness), peluang (opportunities), dan ancaman (threats) dari produk sabun susu kambing.

\section{Pembuatan Luaran}

Dalam kegiatan pengabdian masyarakat ini, terdapat beberapa luaran untuk masyarakat Desa Logandeng dan semuanya berupa non-fisik. Beberapa luaran itu di antaranya ialah buku saku, $e$-book, video dan laporan program kerja. Ebook sederhananya memuat informasi yang sama seperti buku namun memiliki kelebihan yaitu dapat memuat video [7]. Pada buku saku juga merupakan $e$-book dan mencakup penjelasan rinci terkait pembuatan sabun susu kambing. Adapun penjelasan ini mencakup komposisi hingga tahapan pembuatan sabun susu kambing.

Terkait hal ini, tim juga sudah melakukan percobaan pembuatan sabun susu kambing terlebih dahulu untuk bisa menentukan komposisi dan tahapan yang tepat dan aman. Kemudian pada pembuatan $e$-book, tim menyusun materi dan isinya selaras dengan hasil laporan program kerja. Laporan program kerja sendiri merupakan keseluruhan hasil analisis dan dokumentasi kegiatan yang dilakukan oleh tim dalam jangka waktu yang telah ditentukan. Lalu, dalam video berisi proses dan penjelasan seluruh program kerja secara lisan untuk masyarakat. Dalam video ini juga mencakup demonstrasi pembuatan sabun susu kambing untuk memudahkan pemahaman masyarakat. Video ini kemudian akan diunggah di youtube.

\section{HASIL DAN PEMBAHASAN}

\section{A. Hasil Analisis Data}

1. Segmenting, Targeting, Positioning (STP) Berikut ini ialah analisis STP dari Produk Sabun Susu Logandeng:

a. Segmenting

Tujuan adanya segmentasi pasar adalah untuk mengidentifikasi pasar mana yang memiliki potensi untuk menjadi sasaran pasar sehingga mampu meningkatkan jumlah kunjungan [8]. Produk Sabun Susu Logandeng hadir dengan memb erikan keutamaan manfaat yang dapat menyehatkan 
dan meremajakan kulit. Sabun Susu Logandeng ditargetkan konsumen pada usia 15-60 tahun yang menekankan pada kualitas, khasiat serta manfaat produk yang nantinya dapat dinikmati oleh konsumen. Tujuannya adalah untuk membangun brand image dari Produk Sabun Susu Logandeng yang merupakan produk Sabun Susu alami yang memiliki kualitas serta beragam manfaat bagi kesehatan kulit remaja hingga orang dewasa. Terlepas dari khasiat serta manfaatnya, Sabun Susu Logandeng dapat diperoleh dengan harga yang terjangkau, sehingga dapat dinikmati setiap kalangan masyarakat.

\section{b. Targeting}

Target pasar (targeting) merupakan sebuah masalah bagaimana memilih persoalan memilih menjaring sekaligus mencapai pasar sasaran (target market) yang berupa produk dari targeting yaitu beberapa bagian pasar yang menjadi fokus kegiatan penjualan [9]. Target dari produk Sabun Susu Logandeng adalah masyarakat dari seluruh kalangan dengan tingkatan ekonomi mulai dari kalangan bawah, menengah, hingga atas yang ingin menggunakan sabun susu alami berkualitas tinggi agar dapat memperoleh kulit lembut dan sehat serta mendukung isu lingkungan.

c. Positioning

Positioning merupakan langkah yang dilakukan perusahaan untuk membangun citra produk demi memperoleh tempat yang baik di pikiran pelanggan [8]. Sabun Susu Logandeng menempatkan positioning-nya pada masyarakat bahwa produk ini merupakan produk alami dengan ribuan manfaat. Selain menawarkan khasiat dari Sabun Susu Logandeng yang dapat menyehatkan kulit, Sabun Susu Logandeng juga memberikan kualitas terbaik dari setiap produk yang diproduksinya agar konsumen dapat merasa puas setelah menggunakan Sabun Susu Logandeng dengan harga yang terjangkau.

2. Strength, Weakness, Opportunity, Threat (SWOT) Berikut ini ialah analisis SWOT dari Produk Sabun Susu Logandeng:

a. Strengths

Produk sabun susu kambing terbuat dari komposisi alami seperti minyak kelapa sawit, minyak olive, soda api, minyak kelapa dan susu kambing sehingga bebas dari zat kimia yang berbahaya bagi kulit. Sabun ini memberikan banyak manfaat bagi kulit seperti melembapkan kulit kering, aman bagi kulit sensitif, mencegah tumbuhnya jeraawat, membersihkan kulit, mendukung mikroorganisme kulit agar tetap sehat dan bisa mengeksfoliasi kulit. Di samping itu, sabun susu ini merupakan produk local yang terbuat dari hasil kekayaan nabati dan hewani Desa Logandeng sehingga terjamin keasliannya. Produk sabun susu ini juga ramah lingkungan dan tidak mengeluarkan biaya yang besar dalam pembuatannya karena menggunakan bahan dasar yang alami.

b. Weaknesses

Produk sabun susu kambing masih dirasa kurang diminati di pasar Indonesia karena masyarakat masih cenderung menggunakan sabun konvensional yang lebih praktis dan mudah didapatkan. Masyarakat pun cenderung masih menyukai sabun berbentuk cair dan non-natural. Di sisi lain, proses pengolahan sabun susu kambing juga memakan waktu yang cukup lama.

\section{c. Opportunities}

Produk sabun susu kambing berpotensi mudah dipasarkan pada masyarakat yang cenderung ingin merawat tubuhnya dengan produk yang baru dan menarik. Produk sabun susu ini juga masih jarang diproduksi sehingga akan memperkenalkan potensi Desa Logandeng khususnya di bidang peternakan. Produk sabun susu ini juga akan menjadi produk kecantikan lokal khas Desa Logandeng disamping produk kuliner dan kerajinan yang sudah ada. Selain itu, produk ini pun menghilangkan sel kulit mati dimana sabun-sabun lain pada umumnya tidak semuanya dapat menghilangkan sel kulit mati.

\section{d. Threats}

Adapun yang dapat menjadi ancaman untuk produk sabun susu kambing ini ialah standarisasi mutu produk dan SDM pekerja sabun susu kambing yang masih sangat diperlukan. Selain itu, sudah adanya pesaing yang memulai usaha sabun susu terlebih dahulu. Ditambah lagi, sabun susu termasuk dalam jenis sabun kesehatan sehingga hanya sedikit dari total konsumsi sabun di pasaran. Di sisi lain, peralatan pembuatan sabun susu yang masih manual sehingga membuat produksi menjadi kurang efektif.

\section{B. Hasil Luaran}

\section{Pembuatan Produk Sabun Susu Kambing}

Seperti yang sudah disebutkan sebelumnya, tim memutuskan untuk secara khusus mengembangkan usaha sabun susu dari hewan ternak kambing. Produk sabun susu yang tim usulkan merupakan sabun susu alami dalam bentuk sabun batangan. Pembentukan sabun batang dihasilkan dari reaksi penyabunan antara minyak dan $\mathrm{NaOH}$ [10]. Tim juga sudah melakukan percobaan pembuatan sabun susu kambing. Adapun bahan-bahan yang tim gunakan di antaranya yaitu: minyak kelapa sawit (450 gr), minyak olive (450 gr), susu kambing segar (285 gr) dan soda api atau Naoh (108gr). Komposisi ini untuk pembuatan satu box cetakan sabun dengan ukuran $(29$ x 9,5 x 9,5) cm. Gambar 1 menunjukkan salah satu tahapan pembuatan sabun susu kambing yaitu tahap memasukan campuran susu dan soda api ke campuran minyak. Sedangkan pada gambar 2 menunjukkan hasil percobaan pembuatan produk sabun susu kambing oleh tim yakni berupa sabun batangan. 


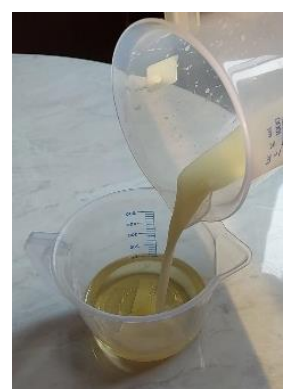

Gambar 1. Salah satu tahap percobaan pembuatan sabun susu kambing

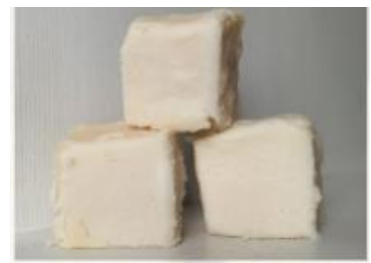

Gambar 2. Hasil percobaan pembuatan produk sabun susu kambing oleh tim

Selain melakukan percobaan pembuatan sabun susu kambing, tim juga membuat desain kemasan produk sabun susu kambing. Tim memutuskan untuk membuat konsep desain kemasan yang ramah lingkungan, elegan dan simple, dapat memberikan pengalaman membuka kemasan yang berbeda dan bagian atas kemasan yang transparan. Konsep desain kemasan di bagian belakang bertuliskan komposisi dan manfaat. Sedangkan di bagian depannya bertuliskan logo produk sabun susu kambing. Konsep desain kemasan ditunjukkan di gambar 3.

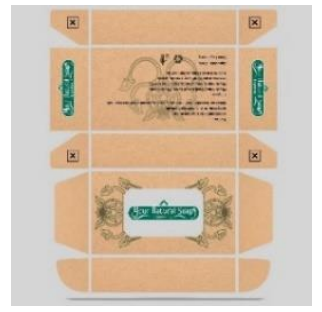

Gambar 3. Konsep desain kemasan produk sabun susu kambing

Adapun logo dari kemasan produk tersebut bertuliskan "Your Natural Soap - Logandeng" seperti yang ditunjukkan di gambar 4.

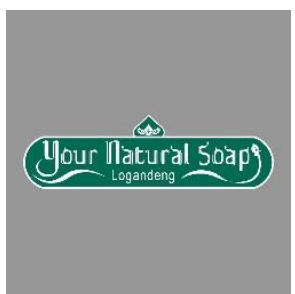

Gambar 4. Logo kemasan produk sabun susu kambing

\section{Buku Saku}

Setelah melakukan percobaan dan mendesain kemasan produk sabun susu kambing, tim merumuskannya dalam sebuah buku saku agar dapat dimanfaatkan oleh masyarakat Desa Logandeng. Buku saku ini berbentuk non-fisik (e-book) yang berjudul "Peluang Usaha Sabun Susu Kambing". Dalam buku saku ini, mencakup dari alat dan bahan, tahapan pembuatan, konsep desain kemasan, serta analisis STP dan SWOT. Berikut pada gambar 5, dapat dilihat salah satu halaman dalam buku saku yang menjelaskan tahapan pembuatan sabun susu kambing.

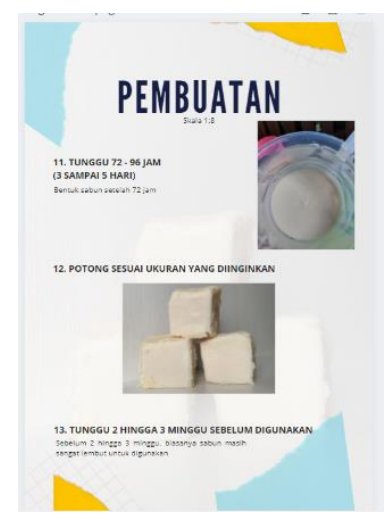

Gambar 5. Salah satu halaman buku saku yang menjelaskan tahapan pembuatan sabun susu kambing.

\section{E-book Potensi Desa}

Hasil dari program kerja tim yang selanjutnya adalah $e$-book yang berisi tentang peta dan potensi Desa Logandeng, permasalahan yang sedang dihadapi Desa Logandeng dan juga solusi untuk permasalahan tersebut, seperti kurangnya pengembangan olahan dari potensi Desa Logandeng yang berupa susu kambing dan tim pada e-book ini menjelaskan bagaimana sabun susu kambing yang diberi merek "Your Natural Soap". Berikut pada gambar 6 dapat dilihat sampul dari $e$-book potensi Desa Logandeng.

\section{Video}

Video potensi desa yang dibuat oleh tim merupakan penjelasan menggunakan visual yang diharapkan akan mudah memahami maksud dari e-book yang telah tim buat. Hal ini dikarenakan setiap program kerja diadakan secara online atau daring, maka penjelasan lebih lanjut menggunakan video ini agar masyarakat Desa Logandeng lebih mudah untuk memahami dan tidak ada batasan waktu atau dapat diputar kembali nantinya. Berikut pada gambar 7, gambaran dari salah satu cuplikan video potensi Desa Logandeng. 


\section{KESIMPULAN}

Berdasarkan program kerja pengabdian masyarakat tim di Desa Logandeng dapat ditarik simpulan sebagai berikut. Desa Logandeng memiliki potensi yang besar di bidang peternakan khususnya hewan ternak kecil yakni kambing. Oleh karena itu, tim mengusulkan produk sabun susu kambing sebagai potensi usaha di Desa Logandeng. Pembuatan produk sabun susu kambing ini diharapkan dapat menjadi produk khas Desa Logandeng dan menjadi produk kecantikan lokal khas desa ini di samping produk kuliner dan kerajinan. Semoga jurnal pengabdian ini dapat menjadi referensi untuk para penulis lain dan dapat memperbaiki, mengembangkan serta menyempurnakan program kerja yang diusulkan oleh tim ini.

\section{UCAPAN TERIMAKASIH}

Ucapan terima kasih kami haturkan kepada Lembaga Penelitian dan Pengabdian kepada Masyarakat (LPPM) Universitas Atma Jaya Yogyakarta yang sudah memberikan kesempatan serta memfasilitasi program pengabdian ini. Selain itu, kami mengucapkan terima kasih juga untuk temanteman yang saling memberi motivasi untuk membantu kelancaran pembuatan program kerja pengabdian masyarakat di Desa Logandeng.Kami berharap karya tulis ini dapat memberikan wawasan dan pengetahuan kepada masyarakat, teman-teman, dan pada kami khususnya untuk selanjutnya dapat bermanfaat bagi masyarakat Desa Logandeng.

\section{DAFTAR PUSTAKA}

[1] BPS Kabupaten Gunungkidul, "Kecamatan Playen Dalam Angka 2020," Gunungkidul, 2020.

[2] B. Bungin, Penelitian Kualitatif. Jakarta: Kencana Predana Media Group, 2011.

[3] M. S. Seran, "Kewirausahaan Sosial: Suatu Strategi Pengembangan Potensi Desa Melalui Program Dana Desa," J. Poros Polit., pp. 18-23, 2019, [Online]. Available:

http://jurnal.unimor.ac.id/JPP/article/view/452.

[4] F. Tjiptono, G. Chandra, and D. Adriana, Pemasaran Strategik. Yogyakarta: Andi, 2007.

[5] A. Coman and R. Boaz, "Focused SWOT: Diagnosing Critical Strengts and Weaknesses," Int. J. Prod. Res., vol. 47, no. 20, pp. 5677-5689, 2009, [Online]. Available: https://www.tandfonline.com/doi/abs/10.1080/0020 7540802146130.

[6] F. Rangkuti, Analisis SWOT Teknik Membedah Kasus Bisnis. Jakarta: PT. Gramedia Pustaka Utama, 2001.

[7] S. A. Rodhiah and L. Roza, "Hasil Analisis Kebutuhan Pengembangan Ebook Berbasis Multipel Representasi," in Prosiding Seminar Nasional Pendidikan Fisika FITK UNSIQ, 2020, vol. 2, no. 1, pp. 143-149.

[8] F. Fitria Rismawati, S. Wahyuni, and J. Widodo, "Strategi Pemasaran STP (Segmenting, Targeting,

Positioning) Larissa Aesthetic Center Cabang Jember," J. Pendidik. Ekon. J. Ilm. Ilmu Pendidikan, Ilmu Ekon. dan Ilmu Sos., vol. 13, no. 2, p. 68, 2019, doi: 10.19184/jpe.v13i2.10793.

[9] R. Kasali, Membidik Pasar Indonesia Segmenting, Targeting dan Positioning. Jakarta: PT. Gramedia Pustaka Utama, 2011.

[10] Purwanto, "Pengertian Sabun: Definisi Jenis Bentuk Karakteristik Bahan Pembuatan Sabun," adev.co.id, 2021. https://adev.co.id/pengertian-sabun-dandefinisi-sabun-bentuk-dan-jenis-sabun/.

\section{PENULIS}
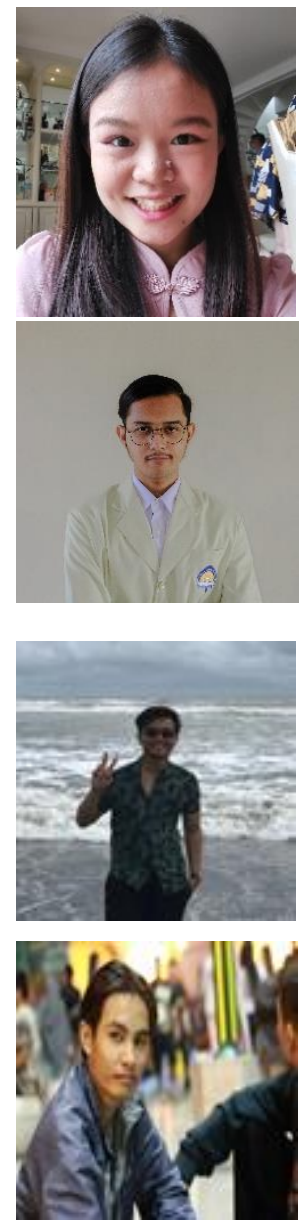

Kadek Bramantya Krisnanta Putra Prodi Informatika, Fakultas Teknologi Industri

Universitas Atma Jaya Yogyakarta

\section{Galih Indra Kusumajati}

Prodi Sistem Informasi, Fakultas

Tekonologi Industri

Universitas Atma Jaya Yogyakarta

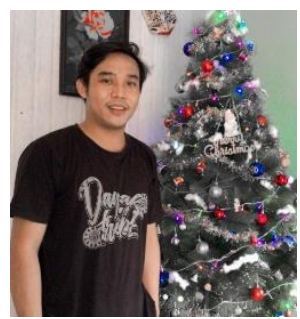

\section{Jepri Yanus Buulolo}

Prodi Sosiologi, Fakultas Ilmu Sosial Dan Ilmu Politik

Universitas Atma Jaya Yogyakarta

\section{Gregorius Niarwin}

Prodi Informatika, Fakultas Teknologi Industri

Universitas Atma Jaya Yogyakarta 


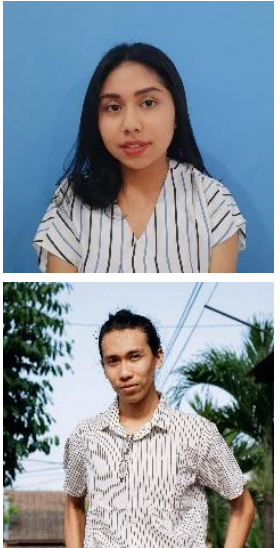

Giovanny Inan Jelmau

Prodi Ilmu Komunikasi, Fakultas Ilmu

Sosial dan Ilmu Politik

Universitas Atma Jaya Yogyakarta

\section{Ulul Azmi}

Prodi Ilmu Komunikasi, Fakultas Ilmu Sosial dan Ilmu Politik

Universitas Atma Jaya Yogyakarta

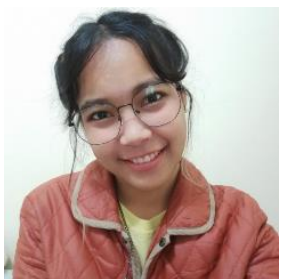

\section{Aulia Rahmadhani}

Prodi Akuntansi, Fakultas Bisnis dan

Ekonomi

Universitas Atma Jaya Yogyakarta

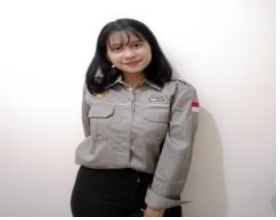

\section{Emilia Vicka Kurniastuti}

Prodi Teknik, Fakultas Teknik Sipil

Universitas Atma Jaya Yogyakarta

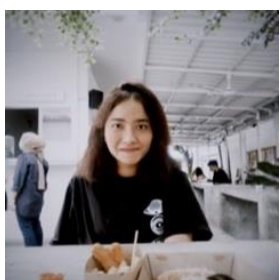

\section{Surya Putri Arum S.K}

Prodi Manajemen, Fakultas Bisnis dan Ekonomi

Universitas Atma Jaya Yogyakarta 